\title{
Effectiveness of physical education to promote motor competence in primary school children
}

\author{
Vítor P. Lopes, David F. Stodden \& Luis P. Rodrigues
}

To cite this article: Vítor P. Lopes, David F. Stodden \& Luis P. Rodrigues (2017): Effectiveness of physical education to promote motor competence in primary school children, Physical Education and Sport Pedagogy, DOI: 10.1080/17408989.2017.1341474

To link to this article: http://dx.doi.org/10.1080/17408989.2017.1341474

\section{曲 Published online: 22 Jun 2017.}

Submit your article to this journal $\pi$

Q View related articles $₫$

View Crossmark data $\nearrow$ 


\title{
Effectiveness of physical education to promote motor competence in primary school children
}

\author{
Vítor P. Lopes (1D ${ }^{a, b}$, David F. Stodden ${ }^{c}$ and Luis P. Rodrigues ${ }^{b, d}$ \\ ${ }^{a}$ Sport Science Department of School of Education of Polytechnic Institute of Bragança, Bragança, Portugal; \\ ${ }^{b}$ Research Center in Sports Sciences, Health Sciences and Human Development (CIDESD); ${ }^{\circ}$ Department of Physical \\ Education and Athletic Training, University of South Carolina, Columbia, SC, USA; Instituto Politécnico de Viana do \\ Castelo, Escola Superior Desporto e Lazer, Melgaço, Portugal
}

\begin{abstract}
Background: Motor skill (MS) competence is an important contributing factor for healthy development.

Purpose: The goal was to test the effectiveness of primary school physical education (PE) on MS and physical fitness (PF) development.

Methods: Three classes ( $n=60$, aged $9.0 \pm 0.9)$ were randomly assigned to three diverse conditions during a school year: two PE lessons/week (PE-2), three PE lessons/week (PE-3), and no PE lessons control group (CG). BMI, skinfolds, PF (9-min run/walk, sit-up, modified pull-ups), gymnastics, soccer, handball, basketball and track-and-field skills were evaluated. Effect sizes $(d)$ were reported as magnitude of change.

Results: Skinfolds significantly increased only in CG $(d=1.21)$. PF composite $z$-scores improved in PE-3 $(d=0.61)$, but decreased in PE-2 $(d=0.57)$, and had no changes in CG. Statistically significant improvement was verified in gymnastics and handball skills in both experimental groups (gymnastic: $d=2.95$ and $d=2.61$ for PE-3 and PE-2, respectively; handball: $d=1.87$ and $d=0.57$ for PE-3 and PE-2, respectively), and no changes were seen in CG. In soccer, there were improvements only in the PE-3 $(d=0.55)$, and in basketball only in PE-2 $(d=0.46)$. There were no changes in any group for track-and-field skills.

Conclusions: PE programs can effectively promote PF and MS development.
\end{abstract}

\section{ARTICLE HISTORY}

Received 15 October 2016

Accepted 5 May 2017

\section{KEYWORDS}

Motor skills; motor

coordination; physical fitness;

intervention program; sports

The prevalence of childhood obesity and associated comorbidities are a global problem (WHO 2016). Research indicates that the development of motor competence may be an important contributing factor for the development of positive or negative weight trajectories and physical fitness (PF) across childhood (D'Hondt et al. 2011; Lopes et al. 2012b; Rodrigues, Stodden, and Lopes 2016). Several recent cross-sectional (D'Hondt et al. 2011) and longitudinal (Lopes et al. 2012b) studies demonstrate an inverse relationship between measures of motor competence and body weight status in both sexes across various ages (i.e. 5-12 years). The strength of this relationship also increases over time (D’Hondt et al. 2011; Lopes et al. 2012).

According to systematic reviews, children of all ages who are less motor competent are less active (Logan et al. 2015; Barnett et al. 2016), which may also augment unhealthy weight gain. Furthermore, longitudinal evidence suggests that being skilled as a child is associated with being more active (Barnett et al. 2009; Lopes et al. 2011) and fit (Barnett et al. 2008) into late childhood and 
adolescence. Thus, developing an adequate foundation of motor competence may provide a protective effect against decreasing physical activity and unhealthy weight gain that generally occur across childhood (Robinson et al. 2015). This evidence aligns with a proposed developmental and recursive conceptual model (Stodden et al. 2008) that suggests negative obesity trajectories may be triggered by the cumulative effects of lower motor competence that may reduce movement opportunities (i.e. physical activity) (Logan et al. 2017), PF (Cattuzzo et al. 2016), and perceived motor competence during childhood (Robinson 2011). Overall, low motor competence is hypothesized to result in decreased participation in a variety of activities and/or sports in middle to late childhood, thus leading to a negative spiral of disengagement from an active lifestyle (Robinson et al. 2015).

Unfortunately, the development of motor competence, as well as physical activity and fitness levels, is decreasing in school age children (Trost et al. 2002; Tester, Ackland, and Houghton 2014). Children should develop a strong foundation of fundamental motor skills (MSs) in early childhood (Gallahue, Ozmun, and Goodway 2011), which can be transitioned to more specialized MSs. For this to happen, regular involvement in context-specific and developmentally appropriate movement experiences is critical.

The United Nations Educational, Scientific and Cultural Organization (UNESCO) recently called upon countries to act on the quality of physical education (PE) as an essential key point to learn life skills and to develop positive patterns of behavior (UNESCO 2016). Nevertheless, there is a lack of research addressing the effectiveness of PE in primary schools for the acquisition of fundamental and specific MSs. Most studies involving PE have focused on PF effects, like cardiorespiratory fitness, strength, body fat, and/or physical activity promotion (Shephard and Lavallée 1993a, 1994; Lucertini et al. 2013; Reed et al. 2013). In addition, the dose-response question is not always adequately addressed in MS development research. To our knowledge, no studies to date have compared the effects of different weekly PE lesson frequency on motor competence or PF. Most previous studies have implemented a PE program and compared the results with a non-PE program control group (CG) or with a regular PE (most of the times with classes once a week) taught by a non-specialist (Shephard and Lavallée 1993b, 1994; Lucertini et al. 2013). Therefore, the effect of weekly frequency of PE classes on motor competence and other healthrelated variables continues to be debated. Although there is no clear policy by the Portuguese ministry of education on the weekly frequency of $\mathrm{PE}$, the majority of schools offer two lessons per week (CNAPEF 2013). PE professionals claim the need for at least three classes per week (CNAPEF 2013).

A systematic review about the effectiveness of PE and school sport interventions targeting physical activity, motor competence and enjoyment of physical activity, revealed a lack of high quality evaluations and statistical power to draw conclusions concerning the efficacy of the interventions conducted (Dudley et al. 2011). A recent meta-analysis study (Morgan et al. 2013) targeting fundamental movement skill interventions in youth, found a significant intervention effect with a relatively large effect size (standardized mean difference $=1.42$ ) for overall gross motor competence. Logan and Robinson (Logan et al. 2012), in a meta-analysis about the effectiveness of MS interventions in children, actually demonstrated a non-significant relationship between effect size and duration of the intervention (in minutes). Unfortunately, studies documented in the Logan et al. study were not comparable from a dose-response perspective as results were based on across study and not within study comparisons.

We believe that adequately powered and effective intervention studies targeting specific movement skills in primary schools are necessary to improve motor competence and to examine its effect on health variables. The development of motor competence during childhood is crucial for a healthy life, since it will allow individuals to successfully participate in a variety of leisure or sport-related (individual or team) activities across the lifespan (Barnett et al. 2009; Breuer and Wicker 2009). 
The aim of this research was to test the effect of two or three PE lessons per week, compared to a control condition with no PE, on MS development and PF in primary school children throughout one school year.

\section{Methods}

\section{Design of the study}

This is a study with a pre- and post-test quasi-experimental design implemented during a school year (10 months). The assessment of PF and body dimensions was conducted at the beginning and at the end of the school year. MSs were evaluated at the beginning and at the end of their respective instructional unit.

Three classes from third and fourth grades, attending the same primary school were randomly assigned to three different conditions: two PE lessons per week (PE-2); three PE lessons per week (PE-3) and the third class did not have any PE lesson, thus constituting the CG. The same specialist teacher in PE taught all classes. This PE teacher had a degree in sport science, professional in-service training in $\mathrm{PE}$ and five years of $\mathrm{PE}$ teaching experience. Fifty-eight lessons were taught during the school year to children within group PE-2, and 88 lessons to children within group PE-3. All classes had a 30-min free playtime, every day, during school time apart from PE lessons.

The main goal of the PE intervention program was to learn and develop initial MSs related to specific sports, and to develop PF. The PE program was designed to include specific MSs, namely skills from gymnastics, soccer, Olympic handball, basketball and track and field. The program was split in five instructional units, according to specific skills. The number of school year' sessions were equally divided for each instructional unit. The sessions were divided in three parts; an initial warm up (5-10 $\mathrm{min})$, a main instructional/practice session (25-30 $\mathrm{min}$ ) and a final part (4-8 min). The initial part consisted mainly in warming up with both continuous and interval running exercises, and also callisthenic exercises like sit-ups, push-ups and body weight squats. The main session was specifically organized for learning MSs within the specific instructional unit. The final part of the session consisted mainly of strength and flexibility exercises. The total duration of each session was 45-50 min. Table 1 shows both handball and gymnastics unit plans as an example.

The intervention followed the school year calendar of Portugal's educational system, starting in September and ending in June of the next year. There are three holiday breaks: (a) for Christmas/new year (about 2 weeks), (b) Carnival (about a week) and (c) Easter (about 2 weeks). In Portugal, PE is part of the national curriculum in primary education: however, not all schools or classes offer PE in the actual curriculum due to constraints relating to a lack of facilities, equipment or human resources. Specific to this project, the interventions took part in a school that did not offer PE classes. The teacher was hired just for this project.

\section{Participants}

Sixty children of both sexes from three classes of third and fourth graders ( $9.0 \pm 0.9$ years) participated in the study. Each class had 20 children with approximately equal numbers of boys and girls.

Most of the children (68.4\%) were normal weight according to the International Obesity Taskforce cut-off values for body mass index (BMI), $8.3 \%$ were underweight, $20 \%$ were overweight and $3.3 \%$ were obese. No differences were found among classes in the percentage of children for each weight status. All children were requested to self-assess their pubertal development (BergKelly and Erdes 1997), and all of them were classified in stage 1 of Tanner's sexual maturity stages (Marshall and Tanner 1970, 1969).

Children's attendance and participation in the experimental groups was higher than $>85 \%$, with no significant differences between the two experimental groups, and data from all participants were 
Table 1. Handball and gymnastic instructional unit plans.

\begin{tabular}{|c|c|c|}
\hline & Handball instructional unity & Gymnastic instructional unity \\
\hline Goals & $\begin{array}{l}\text { Initiate children in the practice of basic handball skills: } \\
\text { - Ball handling } \\
\text { - Catching, throwing, dribbling, shooting, passing and } \\
\text { - feinting } \\
\text { - Playing together } \\
\text { - Making decisions } 2 \text { against } 1 \\
\text { - Tactically clever positioning } \\
\text { - Taking up } 1 \text { against } 1 \text { situations } \\
\text { - } \text { Coopending an area }\end{array}$ & $\begin{array}{l}\text { Initiate students in the practice of elementary gymnastic skills: } \\
\text { - Forward roll } \\
\text { - Backward roll } \\
\text { - Headstand } \\
\text { - Cartwheel } \\
\text { - Leapfrog }\end{array}$ \\
\hline Contents & $\begin{array}{l}\text { Execute multiple ball control movements } \\
\text { Throw the ball with one hand over the shoulder against } \\
\text { the wall and against a moving target } \\
\text { In a situation of collective competition }(3 \times 3) \text {, throw the } \\
\text { ball with one hand over the shoulder against a moving } \\
\text { target } \\
\text { Dribbling the ball } \\
\text { Standing in front of a colleague, pass and receive the ball } \\
\text { Displace and pass and receive the ball from a colleague } \\
\text { Dribbling the ball with opposition }-1 \times 1 \text { situation } \\
\text { Shooting in support against the net } \\
\text { Shooting in suspension } \\
\text { Game situation } 2 \times 2 \text { open passing lanes } \\
\text { In a running situation pass and receive the ball from a } \\
\text { colleague } \\
\text { Dribbling the ball and run in a zig-zag } \\
\text { Shooting to the goal } \\
\text { Jump and shooting in suspension to the goal } \\
\text { In } 3 \times 3 \text { game situation, open passing lanes, and shoot at } \\
\text { goal when you have free space } \\
\text { In the } 3 \times 3 \text { game situation, when on defense, adopt the } \\
\text { basic position defending individually } \\
\text { In the } 5 \times 5 \text { game situation, open passing lanes and shoot } \\
\text { at goal when you have free space } \\
\text { In the } 5 \times 5 \text { game situation, when on defense, adopt the } \\
\text { basic position defending individually }\end{array}$ & $\begin{array}{l}\text { Exercises for learning and improving the skills indicated } \\
\text { Exercises include situations that facilitate the movements, } \\
\text { like inclined planes, and also situations with manual help } \\
\text { by the teacher } \\
\text { The class organization is mostly in group activity booth } \\
\text { alternated and parallel group activity }\end{array}$ \\
\hline
\end{tabular}

included for analysis. These children did not participate in any extracurricular organized sports activities.

Permission was granted by the local school authorities and from the school director. All parents or guardians gave informed consent and all children assented to participate. This study was approved by the ethics committee of the institution of the first author.

\section{Somatic measures}

Height was recorded to the nearest $0.1 \mathrm{~cm}$ using a portable stadiometer (Seca 213, Seca Medical Measuring Systems and Scales, Hamburg, Germany). Mass was measured in light clothing without shoes using a portable digital scale (Seca 899, Seca Medical Measuring Systems and Scales, Hamburg, Germany) to the nearest $0.1 \mathrm{~kg}$. BMI was calculated using the standard equation: mass $(\mathrm{kg}) / \mathrm{height}$ squared $\left(\mathrm{m}^{2}\right)$, and BMI $z$-scores were calculated using WHO Reference 2007 (de Onis et al. 2007). Skinfold thickness was measured using a GPM Holtain type caliper (GPM, Suisse) at two standard sites: triceps and medial calf. Measurement were taken on the right side of the body to the nearest $0.1 \mathrm{~mm}$, and measured in triplicate, with the median score recorded. The technical error of measurement was $0.81 \mathrm{~mm}(5.47 \%)$ and $0.47 \mathrm{~mm}$ (3.01\%) for triceps and medial calf respectively. 
The same trained and experienced investigator performed all anthropometric measures for each participant.

\section{PF tests}

Cardiorespiratory fitness was assessed with a 9-min run/walk and meters covered were recorded. Abdominal strength was evaluated using the number of sit-ups in $60 \mathrm{~s}$. Upper body strength was assessed using the number of modified pull-ups.

\section{Motor skills}

\section{Gymnastics skills}

The following skills were evaluated according to the number of errors identified in a list of 10 errors per skill: forward roll, backward roll, headstand and leapfrog in a vault horse of $60 \mathrm{~cm}$ height. The instrument was specially developed for this research. Five gymnastics coaches were asked to identify the most common errors in the execution of each skill. A final consensus list of 10 errors per skill was built, based on the most frequent errors mentioned by all coaches.

Test re-test reliability, determined with intraclass correlation coefficient (ICC), for the present study was ICC $=0.99$ for all items.

\section{Soccer skills}

The following skills were assessed according to the test battery recommended by the Portuguese Football Federation: passing and receiving, juggling the ball, dribbling and kicking to the goal. A size 4 (circumference of $63.4-66 \mathrm{~cm}$ ) soccer ball was used for all tests.

Passing and receiving - for $20 \mathrm{~s}$ the child continuously kicked the ball to a target on a wall (and received the rebound) from a distance of $2 \mathrm{~m}$. The highest number of successful attempts (receive the ball in a controlled manner), in three trials of $20 \mathrm{~s}$ were registered.

\section{$3 \mathrm{~m}$}

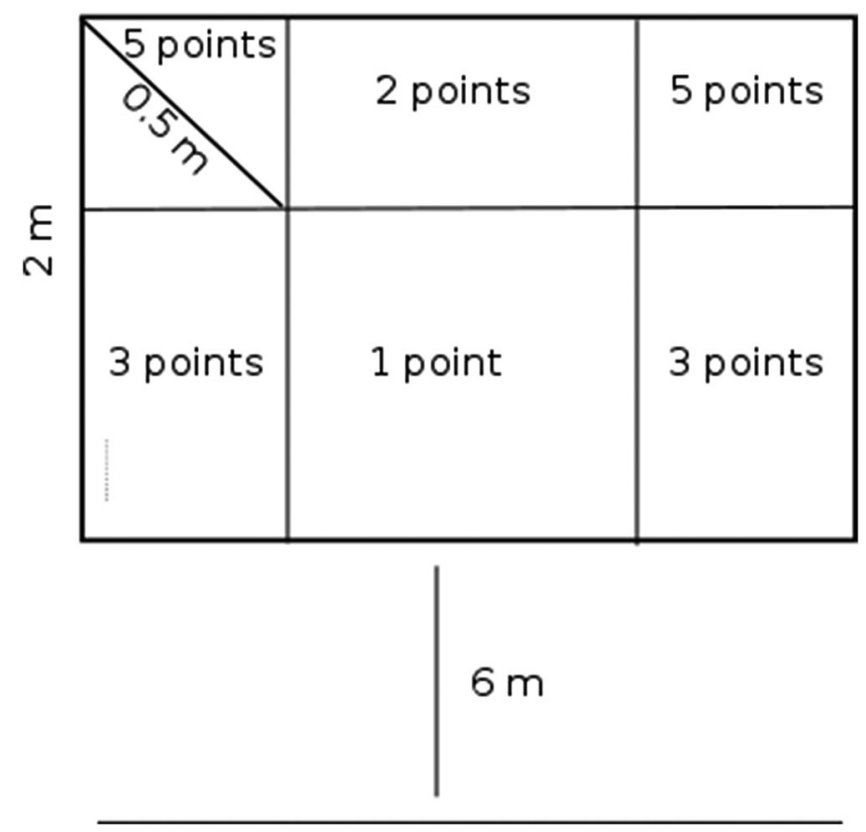

Figure 1. Diagram for shot test precision in soccer and handball. 
Dribbling - each child had three trials to dribble a 15-m distance rounding four vertical obstacles as fast as possible. The lowest time was recorded.

Kicking to the goal - from a distance of $6 \mathrm{~m}$, each child had five trials to kick the ball to a goal target $2 \mathrm{~m}$ high and $3 \mathrm{~m}$ wide. The goal was divided in six areas: two upper corners, two lower corners, upper center and lower center (Figure 1), and according to the area where the ball hit the goal, the child obtained 5, 3, 2 or 1 points, respectively, and zero points if the ball did not reach the goal. Children were informed about the points system. The sum of the five trials was used for data analysis.

Juggling the ball - In a $9 \times 9 \mathrm{~m}$ area, each child juggled the ball with any part of the body except arms and hands. The sum of touches in three trials was recorded. The trial stopped when the ball touched the ground, the hand or arm touched the ball, or the child got out of the delimited area.

Test re-test reliability for the present study varies between ICC $=0.57$ for kicking to the goal and ICC $=0.96$ for juggling the ball.

\section{Olympic handball skills}

As there was no standard battery to assess Olympic handball skills, we developed three tests to assess skills in handball: passing and receiving, dribbling and shooting to the goal.

Passing and receiving - for $20 \mathrm{~s}$ the child continuously throws the ball to a target on a wall (and received it after rebound from the wall) from a distance of $2 \mathrm{~m}$. The highest number of successful attempts in three trials of $20 \mathrm{~s}$ was registered.

Dribbling - each child had three trials to fast dribble a $15-\mathrm{m}$ distance, rounding four vertical obstacles. The lowest time was recorded.

Shooting to the goal - from a distance of $6 \mathrm{~m}$, the child had five trials to throw the ball to a goal target with $2 \mathrm{~m}$ height and $3 \mathrm{~m}$ width. There were two upper corners, two lower corners, upper center and lower center (Figure 1), and according to the area that the ball entered in the goal the child obtained 5, 3, 2, 1 points, respectively, and zero points if the ball did not reach the goal. The points for the five trials were summed up to obtain the child total score.

For all tests, a 44-49-cm circumference ball was used.

Test re-test reliability for the present study varied between ICC $=0.50$ for shooting to the goal and ICC $=0.87$ for the remaining skills.

\section{Basketball skills}

Shooting, passing and dribbling were evaluated according to the AAHPERD Basketball Skills Test (American Alliance for Health Physical Education Recreation and Dance 1984). The ball used had a circumference of $69-71 \mathrm{~cm}$.

Test re-test reliability for the present study varied between ICC $=0.76$ for dribbling and ICC $=0.84$ for passing.

\section{Track-and-field skills}

The performances in the following track-and-field events were evaluated: $40 \mathrm{~m}$ sprint, standing long jump, high jump using the scissors-jump technique and overarm throwing of a tennis ball for distance.

Test re-test reliability for the present study varied between ICC $=0.47$ for $40 \mathrm{~m}$ sprint and ICC $=0.97$ for overarm throwing of a tennis ball for distance.

\section{Data analysis}

Descriptive statistical analyses were run on all variables. Normality of distribution was tested with Kolmogorov-Smirnov and when a non-normal distribution was found, the variable was log transformed.

To examine the global construct of PF, each item was standardized ( $z$-scored) and summed into a PF composite score. The same was done for each group of MSs. 
One-way ANOVA was used to test the difference between classes in pre-test. A factorial 2 (time) $\times$ 3 (class) $\times 2$ (sex) repeated measures ANOVA was used to test for the pre-post intervention's differences between the class condition (control, PE-2, PE-3). When the interaction effect time $\times$ class PE lessons was significant, paired $t$-tests were performed to test for significant changes between pre- and post-test within each class condition. Cohen's ' $d$ ' effect size (standardized mean difference) was calculated for each paired $t$-test and interpreted as small effect if $d=0.2$, medium effect if $d=0.5$, and large effect if $d=0.8$ (Lakens 2013).

\section{Results}

Table 2 shows the descriptive statistic (mean and standard deviation) by each class group in pre- and post-test for BMI and sum of skinfolds (triceps and medial calf).

There were no significant pre-test differences in somatic measures between classes. Repeated measures ANOVA indicate a non-significant time $\times$ class interaction and also a non-significant time $\times$ sex interaction in BMI $z$-scores changes. However, for the sum of skinfolds there was a significant interaction (time $\times$ class) effect $\left(F_{(2,57)}=3.30 ; p=.044\right)$. Paired $t$-tests indicated that a significant increase was only present for the CG $\left(t_{(19)}=-5.43, p<.001, d=1.21\right)$, while there were non-significant changes for the two PE groups.

There were no significant pre-test differences in global PF between classes. Repeated measures ANOVA indicated a significant time $\times$ class interaction $\left(F_{(2,57)}=7.93 ; p=.001\right)$, and a non-significant time $\times$ sex interaction. Paired $t$-test indicated a significant improvement for PE-3 class $\left(t_{(19)}=\right.$ $-2.74, p=.014 ; d=0.61)$, a significant decrease for PE-2 class $\left(t_{(19)}=2.57, p=.019, d=0.57\right)$ and non-significant change for CG.

Descriptive statistics for MS items by condition classes in pre- and post-test and the paired $t$-test results for difference between pre- and post-test are noted in Table 3. There were no significant pre-test differences between classes for any set of MSs.

For gymnastics skills, the repeated measures ANOVA indicated a significant time $\times$ class interaction $\left(F_{(2,57)}=59 ; p<.001\right)$ and a non-significant time $\times$ sex interaction. Paired $t$-tests indicated significant improvements for PE-3 class $\left(t_{(19)}=11.7, p<.001, d=2.95\right)$, and for PE-2 class $\left(t_{(19)}=13.2\right.$, $p<.001, d=2.61$ ), but non-significant changes for the CG.

Concerning the soccer skills, repeated measures ANOVA indicated a significant time $\times$ class interaction $\left(F_{(2,57)}=4.87 ; p=.011\right)$ and a non-significant time $\times$ sex interaction. Paired $t$-tests

Table 2. Descriptive statistic (mean and standard deviation) by class condition in pre- and post-test for BMI and sum of skinfolds (triceps and medial calf).

\begin{tabular}{|c|c|c|c|c|c|c|c|c|}
\hline \multirow[b]{2}{*}{ Week lessons class } & \multicolumn{2}{|c|}{$n$} & \multicolumn{3}{|c|}{ Pre-test } & \multicolumn{3}{|c|}{ Post-test } \\
\hline & Boys & $\overline{\text { Girls }}$ & Boys & Girls & All children & Boys & Girls & All children \\
\hline \multicolumn{9}{|c|}{ Sum of skinfolds (mm) } \\
\hline Control & 13 & 7 & $21.6 \pm 9.9$ & $27.2 \pm 11.2$ & $23.5 \pm 10.5$ & $24.7 \pm 11.1$ & $33.5 \pm 12.8$ & $27.4 \pm 12.1$ \\
\hline PE-2 class & 13 & 7 & $29.3 \pm 13.9$ & $28.5 \pm 12.5$ & $33.3 \pm 21.3$ & $30.4 \pm 13.3$ & $28.9 \pm 8.8$ & $29.9 \pm 11.7$ \\
\hline PE-3 class & 12 & 8 & $23.2 \pm 8.4$ & $27.5 \pm 8.8$ & $24.9 \pm 14.9$ & $25.0 \pm 9.2$ & $26.9 \pm 9.5$ & $25.8 \pm 9.1$ \\
\hline \multicolumn{9}{|l|}{ Height } \\
\hline Control & & & $133.9 \pm 5.4$ & $132.9 \pm 4.2$ & $133.6 \pm 4.9$ & $137.1 \pm 5.7$ & $136.9 \pm 4.2$ & $137.0 \pm 5.1$ \\
\hline PE-2 class & & & $135.1 \pm 4.8$ & $136.8 \pm 9.2$ & $135.7 \pm 6.5$ & $137.9 \pm 5.1$ & $140.6 \pm 8.9$ & $138.9 \pm 6.6$ \\
\hline PE-3 class & & & $132.7 \pm 6.7$ & $130.4 \pm 4.4$ & $131.8 \pm 5.8$ & $136.9 \pm 7.2$ & $133.7 \pm 4.5$ & $135.6 \pm 6.4$ \\
\hline \multicolumn{9}{|l|}{ Weight } \\
\hline Control & & & $29.9 \pm 4.9$ & $31.3 \pm 10.10$ & $30.4 \pm 6.9$ & $31.2 \pm 5.6$ & $35.2 \pm 9.1$ & $32.6 \pm 7.1$ \\
\hline PE-2 class & & & $32.6 \pm 7.4$ & $31.6 \pm 5.4$ & $32.3 \pm 6.7$ & $35.1 \pm 7.6$ & $34.2 \pm 5.5$ & $34.8 \pm 6.9$ \\
\hline PE-3 class & & & $29.1 \pm 4.9$ & $28.3 \pm 5.4$ & $28.8 \pm 5.0$ & $31.6 \pm 5.5$ & $30.1 \pm 4.9$ & $30.9 \pm 5.2$ \\
\hline \multicolumn{9}{|l|}{ BMI $\left(\mathrm{kg} \mathrm{m}^{-2}\right)$} \\
\hline Control & & & $16.6 \pm 1.9$ & $17.5 \pm 4.7$ & $16.9 \pm 3.1$ & $16.6 \pm 2.1$ & $18.6 \pm 3.8$ & $17.3 \pm 2.9$ \\
\hline PE-2 class & & & $17.7 \pm 3.2$ & $16.9 \pm 2.8$ & $17.5 \pm 2,0$ & $18.34 \pm 3.1$ & $17.3 \pm 2.4$ & $17.9 \pm 2.8$ \\
\hline PE-3 class & & & $16.4 \pm 2.0$ & $16.5 \pm 2.2$ & $16.9 \pm 2.7$ & $16.8 \pm 2.0$ & $16.7 \pm 1.8$ & $16.8 \pm 1.9$ \\
\hline
\end{tabular}

Note: Sum of Skinfolds: triceps and calf. BMl: body mass index.

*Significant difference at $p \leq .05$ between pre- and post-test (paired $t$-test). 
Table 3. Descriptive statistics for motor skill items by condition classes in pre- and post-test and paired $t$-test results for differences between pre- and post-test for all children.

\begin{tabular}{|c|c|c|c|c|c|c|c|c|}
\hline \multirow[b]{2}{*}{ Motor skills } & \multirow[b]{2}{*}{ Week lessons class } & \multicolumn{3}{|c|}{ Pre-test } & \multicolumn{3}{|c|}{ Post-test } & \\
\hline & & Boys & Girls & All children & Boys & Girls & All children & \\
\hline \multirow[t]{20}{*}{ Gymnastic } & \multicolumn{8}{|c|}{ Forward roll (\# errors; score range 0-10) } \\
\hline & Control & $4.0 \pm 1.9$ & $4.6 \pm 2.4$ & $4.2 \pm 2.0$ & $4.2 \pm 2.1$ & $6.4 \pm 1.9$ & $5.0 \pm 2.3$ & \\
\hline & PE-2 class & $5.5 \pm 1.7$ & $8.1 \pm 1.2$ & $6.4 \pm 2.0$ & $2.5 \pm 1.1$ & $5.1 \pm 1.8$ & $3.4 \pm 1.8$ & * \\
\hline & PE-3 class & $4.8 \pm 2.2$ & $6.87 \pm 2.4$ & $5.7 \pm 2.4$ & $1.3 \pm 1.5$ & $3.6 \pm 1.2$ & $2.3 \pm 1.8$ & * \\
\hline & \multicolumn{8}{|c|}{ Backwards roll (\# errors; score range 0-10) } \\
\hline & Control & $6.8 \pm 1.0$ & $7.1 \pm 1,5$ & $6.9 \pm 1.2$ & $6.2 \pm 1.5$ & $7.3 \pm 1.1$ & $6.7 \pm 1.4$ & \\
\hline & PE-2 class & $7.2 \pm 0.4$ & $7.7 \pm 0.5$ & $7.35 \pm 0.5$ & $3.5 \pm 2.1$ & $3.9 \pm 0.9$ & $3.6 \pm 1.8$ & * \\
\hline & PE-3 class & $6.8 \pm 0.8$ & $7.6 \pm 0.5$ & $7.2 \pm 0.8$ & $2.4 \pm 1.2$ & $4.5 \pm 1.7$ & $3.3 \pm 1.7$ & * \\
\hline & \multicolumn{8}{|c|}{ Headstand (\# errors; score range 0-10) } \\
\hline & Control & $6.2 \pm 0.6$ & $6.9 \pm 0.4$ & $6.5 \pm 0.6$ & $5.0 \pm 1.4$ & $6.4 \pm 0.9$ & $6.1 \pm 1.3$ & \\
\hline & PE-2 class & $6.9 \pm 0.4$ & $6.7 \pm 0.5$ & $6.8 \pm 0.4$ & $2.6 \pm 2.2$ & $5.6 \pm 0.8$ & $3.65 \pm 2.3$ & * \\
\hline & PE-3 class & $6.8 \pm 0.5$ & $7.1 \pm 0.0$ & $6.9 \pm 0.4$ & $3.1 \pm 2.2$ & $5.1 \pm 2.4$ & $2.6 \pm 0.5$ & * \\
\hline & \multicolumn{8}{|c|}{ Cartwheel (\# errors; score range 0-10) } \\
\hline & Control & $6.1 \pm 2.1$ & $5.9 \pm 2.3$ & $6.0 \pm 2.1$ & $5.7 \pm 2.1$ & $6.4 \pm 2.2$ & $6.0 \pm 2.0$ & \\
\hline & PE-2 class & $7.1 \pm 1.5$ & $8.0 \pm 0.0$ & $7.4 \pm 1.2$ & $3.6 \pm 2.7$ & $5.9 \pm 1.9$ & $4.4 \pm 2.6$ & * \\
\hline & PE-3 class & $6.8 \pm 1.8$ & $7.8 \pm 0.5$ & $7.2 \pm 1.5$ & $3.2 \pm 2.6$ & $5.6 \pm 1.9$ & $4.2 \pm 2.6$ & * \\
\hline & \multicolumn{8}{|c|}{ Leapfrog (\# errors; score range 0-10) } \\
\hline & Control & $10.0 \pm 3.2$ & $11.3 \pm 1.9$ & $10.5 \pm 2.8$ & $9.7 \pm 3.3$ & $10.7 \pm 2.2$ & $10.1 \pm 2.9$ & \\
\hline & PE-2 class & $7.3 \pm 2.6$ & $11.4 \pm 0.7$ & $8.8 \pm 2.9$ & $2.3 \pm 2.7$ & $4.0 \pm 2.8$ & $2.9 \pm 2.8$ & * \\
\hline & PE-3 class & $8.2 \pm 2.5$ & $10.6 \pm 2.9$ & $9.2 \pm 2.8$ & $1.7 \pm 1.4$ & $4.9 \pm 2.0$ & $2.9 \pm 2.3$ & * \\
\hline \multirow[t]{15}{*}{ Soccer } & \multicolumn{8}{|c|}{ Passing and receiving (points) } \\
\hline & Control & $8.0 \pm 3.5$ & $4.7 \pm 1.9$ & $6.9 \pm 3.4$ & $7.2 \pm 2.2$ & $5.7 \pm 2.6$ & $6.7 \pm 2.4$ & \\
\hline & PE-2 class & $6.5 \pm 2.6$ & $3.6 \pm 1.9$ & $5.5 \pm 2.7$ & $10.0 \pm 1.9$ & $4.6 \pm 1.3$ & $8.1 \pm 3.2$ & * \\
\hline & $\begin{array}{l}\text { PE-3 class } \\
\text { Dribbling (s) }\end{array}$ & $7.8 \pm 2.5$ & $4.8 \pm 2.8$ & $6.6 \pm 2.9$ & $9.2 \pm 2.4$ & $6.3 \pm 1.8$ & $8.0 \pm 2.6$ & * \\
\hline & Control & $22.3 \pm 6.5$ & $31.8 \pm 5.9$ & $25.7 \pm 7.7$ & $20.7 \pm 6.2$ & $26.8 \pm 4.0$ & $22.8 \pm 6.2$ & * \\
\hline & PE-2 class & $22.7 \pm 5.6$ & $32.6 \pm 11.4$ & $26.2 \pm 9.2$ & $18.9 \pm 4.4$ & $29.3 \pm 5.5$ & $22.6 \pm 6.9$ & \\
\hline & PE-3 class & $19.6 \pm 4.7$ & $32.5 \pm 7.6$ & $24.8 \pm 8.7$ & $17.5 \pm 3.3$ & $29.4 \pm 7.1$ & $22.3 \pm 7$ & \\
\hline & \multicolumn{8}{|c|}{ Shooting to the goal (points; score range 0-15) } \\
\hline & Control & $6.3 \pm 1.9$ & $5.0 \pm 0.8$ & $5.9 \pm 1.8$ & $6.8 \pm 2.2$ & $4.6 \pm 1.8$ & $6.0 \pm 2.3$ & \\
\hline & PE-2 class & $5.9 \pm 1.9$ & $4.3 \pm 1.1$ & $5.3 \pm 1.9$ & $6.1 \pm 1.7$ & $6.0 \pm 3.2$ & $6.1 \pm 2.3$ & \\
\hline & PE-3 class & $5.8 \pm 1.5$ & $4.9 \pm 1.1$ & $5.4 \pm 1.4$ & $8.2 \pm 3.1$ & $5.9 \pm 1.9$ & $7.3 \pm 2.9$ & * \\
\hline & \multicolumn{8}{|c|}{ Juggling the ball (points) } \\
\hline & Control & $6.9 \pm 2.2$ & $2.4 \pm 1.1$ & $5.4 \pm 2.9$ & $7.2 \pm 3.2$ & $2.9 \pm 1.1$ & $5.7 \pm 3.4$ & * \\
\hline & PE-2 class & $8.5 \pm 4.5$ & $3.0 \pm 0.0$ & $6.6 \pm 4.5$ & $10.2 \pm 6.9$ & $3.3 \pm 0.9$ & $7.8 \pm 6.5$ & \\
\hline & PE-3 class & $6.6 \pm 3.2$ & $2.9 \pm 1.1$ & $4.9 \pm 3.3$ & $9.7 \pm 6.4$ & $3.5 \pm 1.4$ & $7.2 \pm 5.8$ & * \\
\hline Olympic handball & Passing and receivir & (points) & & & & & & \\
\hline & Control & $7.5 \pm 2.5$ & $5.6 \pm 2.8$ & $6.9 \pm 2.7$ & $7.6 \pm 1.9$ & $6.0 \pm 1.8$ & $7.1 \pm 2.0$ & \\
\hline & PE-2 class & $8.7 \pm 1.8$ & $6.0 \pm 2.6$ & $7.8 \pm 2.4$ & $9.5 \pm 1.5$ & $7.6 \pm 1.4$ & $8.8 \pm 1.7$ & * \\
\hline & PE-3 class & $7.2 \pm 1.3$ & $3.4 \pm 1.2$ & $5.7 \pm 2.3$ & $11.3 \pm 2.8$ & $7.9 \pm 1.5$ & $10.0 \pm 2.9$ & \\
\hline & Dribbling (s) & & & & & & & \\
\hline & Control & $15.1 \pm 3.6$ & $21.5 \pm 8.8$ & $17.3 \pm 6.5$ & $17.9 \pm 4.5$ & $23.1 \pm 5.1$ & $19.8 \pm 5.2$ & * \\
\hline & PE-2 class & $14.8 \pm 3.4$ & $22.5 \pm 5.2$ & $17.5 \pm 5.5$ & $15.8 \pm 2.6$ & $26.0 \pm 5.9$ & $19.4 \pm 6.3$ & * \\
\hline & PE-3 class & $14.2 \pm 2.8$ & $23.3 \pm 6.6$ & $17.8 \pm 6.4$ & $20.8 \pm 6.3$ & $40.5 \pm 6.9$ & $28.8 \pm 11.8$ & \\
\hline & Shooting to the goo & (points; score & range 0-15) & & & & & \\
\hline & Control & $6.6 \pm 1.6$ & $5.1 \pm 2.5$ & $6.1 \pm 2.0$ & $5.2 \pm 2.8$ & $3.9 \pm 2.3$ & $4.7 \pm 2.6$ & \\
\hline & PE-2 class & $6.8 \pm 2.7$ & $5.4 \pm 1.7$ & $6.3 \pm 2.5$ & $9.7 \pm 3.6$ & $6.7 \pm 1.7$ & $8.7 \pm 3.3$ & * \\
\hline & PE-3 class & $7.0 \pm 1.9$ & $4.9 \pm 1.3$ & $6.2 \pm 1.9$ & $9.5 \pm 3.6$ & $6.4 \pm 1.7$ & $8.3 \pm 3.3$ & \\
\hline Basketball & Shooting (points) & & & & & & & \\
\hline & Control & $14.9 \pm 4.9$ & $10.1 \pm 3.5$ & $13.3 \pm 4.9$ & $10.5 \pm 6.6$ & $6.3 \pm 5.6$ & $9.0 \pm 6.4$ & * \\
\hline & PE-2 class & $15.9 \pm 7.7$ & $5.9 \pm 4.1$ & $12.4 \pm 8.2$ & $13.7 \pm 8.9$ & $4.1 \pm 5.5$ & $10.4 \pm 9.0$ & \\
\hline & PE-3 class & $17.9 \pm 7.8$ & $3.4 \pm 4.1$ & $12.1 \pm 9.7$ & $8.1 \pm 5.1$ & $2.3 \pm 2.6$ & $5.8 \pm 5.1$ & * \\
\hline & Passing (points) & & & & & & & \\
\hline & Control & $32.6 \pm 9.8$ & $24.7 \pm 9.1$ & $29.9 \pm 10.1$ & $33.2 \pm 6.9$ & $27.1 \pm 6.9$ & $31.1 \pm 7.3$ & \\
\hline & PE-2 class & $40.4 \pm 11.3$ & $27.7 \pm 15.4$ & $35.9 \pm 13.9$ & $50.2 \pm 9.6$ & $40.7 \pm 8.7$ & $46.9 \pm 10.2$ & * \\
\hline & PE-3 class & $37.8 \pm 11.1$ & $20.0 \pm 10.1$ & $30.7 \pm 13.8$ & $47.2 \pm 10.7$ & $33.5 \pm 9.5$ & $41.7 \pm 12.1$ & * \\
\hline & Dribbling (s) & & & & & & & \\
\hline & Control & $31.8 \pm 7.6$ & $53.2 \pm 27.9$ & $39.3 \pm 19.8$ & $32.3 \pm 11.2$ & $44.9 \pm 18.4$ & $36.7 \pm 15.0$ & \\
\hline & PE-2 class & $33.1 \pm 8.9$ & $35.4 \pm 6.6$ & $33.5 \pm 8.1$ & $29.5 \pm 3.0$ & $38.0 \pm 5.9$ & $32.5 \pm 5.8$ & \\
\hline & PE-3 class & $35.3 \pm 5.5$ & $55.7 \pm 19.1$ & $43.4 \pm 16.4$ & $29.3 \pm 3.7$ & $39.1 \pm 7.2$ & $33.2 \pm 7.1$ & * \\
\hline
\end{tabular}


Table 3. Continued.

\begin{tabular}{|c|c|c|c|c|c|c|c|c|}
\hline \multirow[b]{2}{*}{ Motor skills } & \multirow[b]{2}{*}{ Week lessons class } & \multicolumn{3}{|c|}{ Pre-test } & \multicolumn{3}{|c|}{ Post-test } & \\
\hline & & Boys & Girls & All children & Boys & Girls & All children & \\
\hline \multirow[t]{13}{*}{ Track and field } & \multicolumn{8}{|c|}{$40 \mathrm{~m}$ speed running (s) } \\
\hline & Control & $6.7 \pm 0.6$ & $7.3 \pm 0.5$ & $6.9 \pm 0.6$ & $6.4 \pm 0.6$ & $6.7 \pm 0.4$ & $6.5 \pm 0.5$ & * \\
\hline & PE-2 class & $6.7 \pm 0.5$ & $7.0 \pm 0.6$ & $6.8 \pm 0.6$ & $6.5 \pm .02$ & $7.1 \pm 0.7$ & $6.7 \pm 0.5$ & \\
\hline & $\begin{array}{l}\text { PE-3 class } \\
\text { long jump (m) }\end{array}$ & $6.8 \pm 0.4$ & $7.3 \pm 0.5$ & $6.9 \pm 0.5$ & $6.7 \pm 0.3$ & $7.2 \pm 0.4$ & $6.9 \pm 0.5$ & \\
\hline & Control & $2.2 \pm 0.4$ & $1.2 \pm 0.5$ & $1,9 \pm 0.7$ & $2.1 \pm 0.3$ & $1.6 \pm 0.3$ & $1.9 \pm 0.4$ & \\
\hline & PE-2 class & $1.9 \pm 0.2$ & $1.5 \pm 0.3$ & $1.8 \pm 0.3$ & $2.2 \pm 0.3$ & $1.7 \pm 0.3$ & $2.1 \pm 0.4$ & * \\
\hline & \multicolumn{7}{|l|}{ high jump (cm) } & * \\
\hline & Control & $75.7 \pm 12.2$ & $61.4 \pm 3.8$ & $70.8 \pm 12.2$ & $80.4 \pm 9.2$ & $63.6 \pm 11.4$ & $74.5 \pm 12.2$ & \\
\hline & PE-2 class & $75.8 \pm 3.4$ & $70.7 \pm 5.3$ & $74.0 \pm 4.8$ & $83.5 \pm 8.2$ & $74.3 \pm 7.3$ & $80.3 \pm 8.9$ & * \\
\hline & \multicolumn{7}{|l|}{ Throwing (m) } & * \\
\hline & Control & $23.2 \pm 4.2$ & $13.8 \pm 1.9$ & $19.9 \pm 5.8$ & $23.4 \pm 4.9$ & $12.3 \pm 3.8$ & $19.5 \pm 7.0$ & \\
\hline & PE-2 class & $23.4 \pm 3.4$ & $12.5 \pm 3.0$ & $19.6 \pm 6.2$ & $24.1 \pm 4.3$ & $12.2 \pm 5.8$ & $19.9 \pm 7.5$ & \\
\hline & PE-3 class & $19.5 \pm 3.6$ & $8.5 \pm 3.9$ & $15.1 \pm 6.6$ & $20.6 \pm 5.3$ & $9.3 \pm 3.1$ & $16.1 \pm 7.2$ & \\
\hline
\end{tabular}

*Significant at $p \leq .05$ (paired $t$-test).

indicated significant improvements only for the PE-3 class $\left(t_{(19)}=-2.47, p=.023, d=0.55\right)$, and non-significant changes for the PE-2 class and CG.

For Olympic handball skills, the repeated measures ANOVA indicated a significant time $\times$ class interaction $\left(F_{(2,57)}=6.68 ; p=.002\right)$ and a non-significant time $\times$ sex interaction. Paired $t$-tests indicated significant improvements for PE-3 class $\left(t_{(19)}=-3.37, p=.003, d=1.87\right)$, and for PE-2 class $\left(t_{(19)}=-2.72, p=.014, d=0.57\right)$, but non-significant changes for the CG.

Regarding the basketball skills, repeated measures ANOVA indicated a significant time $\times$ class interaction $\left(F_{(2,57)}=3.73 ; p=.03\right)$ and a non-significant time $\times$ sex interaction. Paired $t$-tests indicated significant improvements only for PE-2 class $\left(t_{(19)}=-2.054, p=.05, d=0.46\right)$.

For track-and-field skills, repeated measures ANOVA indicated a non-significant time $\times$ class interaction, and a non-significant time $\times$ sex interaction.

\section{Discussion}

The purpose of this quasi-experimental design study was to test the effectiveness of different doses of PE on MS development and PF in primary school children throughout a school year.

The impact of PE on multiple skills across multiple specialized instructional units was found to be similar for both sexes. In general, PE lessons had a positive impact on the development of specific MSs in all sports but track and field. Even two lessons per week led to an improvement in MS competence, especially in gymnastic and basketball skills. The magnitude of the effect was very high in gymnastic skills for both PE-3 $(d=2.95)$ and PE-2 $(d=2.61)$ class conditions. In soccer, only PE-3 class had a significant improvement with an effect of medium magnitude $(d=0.55)$. For Olympic handball skills, both PE-2 and PE-3 classes showed a significant proficiency improvement, although the magnitude of the effect was much larger in the three PE sessions per week group (PE-3 $d=1.87$; PE-2 $d=0.57$ ). In basketball, there was a significant improvement only for the PE-2 class. In addition, we found non-significant changes for any group in the track-and-field skills.

The main results of the present research showed that PE lessons were effective in learning and developing specific MSs. In consonance with this Chen et al. (2016) found that PE contributed to improving fourth- and fifth-grade students' manipulative skill (soccer dribbling, passing, and receiving, overhand throwing, and striking with a racket). Also Dudley et al. (2011) in a meta-analysis study found that PE was efficacious in improving movement skill proficiency in primary school children.

The differences in the effect of PE on improving motor competence in different sports skills may have been due to the fact that some skills were entirely new to children while other skills were more 
familiar to the children, resulting on a very different range of expected improvement. For example, gymnastics skills were completely novel skills for most children, while soccer skills are regularly used by children in their free play and recreation activities in Portugal. Thus, it is not surprising that the effect size was higher in gymnastic skills, where the baseline results were low. The lack of effect for track-and-field skills are probably due to the fact that the skills used are more familiar (i.e. involving running, jumping and throwing) that children are using in their everyday play. That could have resulted in a better baseline value for these skills that was more difficult to improve. Since no qualitative observations on children's movement patters were made, we cannot speculate about a possible change in movement specific coordination patterns.

In line with the present results, Beurden et al. (2003) found significant improvement in fundamental skills mastery in primary school children exposed to modified existing PE lessons. Also Ericsson (2008) found progress in children's MSs with extended PE lessons (daily versus twice a week). McKenzie et al. (1998) found an improvement in children's manipulative skills taught by PE specialists. It is important to emphasize that the PE curriculum of the present study included sports skills, while previous studies only included fundamental MSs. The results of this study are not consistent with the dose-response prediction as it would be expected for PE-3 class to have higher improvement in all MSs, which was not the case. Similary, Logan et al. (2012) found a non-significant relationship between effect size of PE interventions and duration of the intervention (in minutes).

Recent research has shown that the development of a broad base of MSs may be a crucial factor for adopting an active lifestyle (Lopes et al. 2011; Robinson et al. 2015; Rodrigues, Stodden, and Lopes 2016). That is, the development of motor competence increases the possibility for children to participate actively in sports and games either formally or informally. Thus, higher levels of motor competence may be a protective factor against decreasing levels of habitual physical activity and the development of unhealthy body weight (Robinson et al. 2015). However, a large number of studies on PE focus mainly on the potential of PE to provide enough amount of physical activity (regarding all indicators of volume and intensity); that is, its contribution to the achievement of physical activity recommendations (Jago et al. 2009; Frömel et al. 2016). Less research was devoted to studying the potential of PE in primary education to develop MSs and especially specific MSs. PE lessons are an ideal setting to improve child motor competence and increase physical activity for optimal health (Beurden et al. 2003; Cohen et al. 2015).

The results showed that two PE lessons per week were not enough to improve PF, since only children with three PE lessons per week significantly improved global PF, as indicated by sum of PF items $z$-cores. Three lessons per week had a medium impact on the improvement of PF as indicated by the effect size value $(d=0.61)$. These results are in line with Lucertini et al. (2013), who found an improvement of strength (several indicators) in children taught by PE teachers compared to nonspecialist teacher (from $4.1 \%$ to $72.6 \%$ ). Improvements in muscular strength were also found by Löfgren et al. (2013), although the PE programs of these studies were designed to specifically include strength training and additionally had 40 min per day of PE lessons for 2 years. In the Trois Riviéres' study, improvement in strength were also found ( $75 \%$ for shoulder flexion, $117 \%$ for elbow flexion, $116 \%$ for handgrip, $83 \%$ for hip flexion, $67 \%$ for knee flexion and $80 \%$ for knee extension) (Shephard and Lavallée 1994) along with a rather small (from 3.9\% to $9.8 \%$ in boys and from $0.7 \%$ to $9.8 \%$ in girls) increase in cardiorespiratory fitness (Shephard and Lavallée 1993b). In a health-related PE curriculum, Sallis et al. (1997) also found improvement on abdominal strength and endurance and cardiorespiratory endurance.

Children in both experimental classes did not increase adiposity during a full year, while children in the CG had a significant increase in their sum of skinfold. These results were quite similar to those demonstrated by de Greeff, Hartman (de Greeff et al. 2016) who found that the intervention group BMI did not change during an intervention period of 22-weeks, whereas a CG demonstrated a significant increase. While it is well known that improving weight status or adiposity levels is difficult to accomplish without a sustained multicomponent intervention, several studies indicate that a higher motor competence, fitness and physical activity levels may help to control them across time (Lopes 
et al. 2012a; D'Hondt et al. 2014; Rodrigues, Stodden, and Lopes 2016). Studies addressing the role of PE (Reed et al. 2013) found no significant changes in BMI with $45 \mathrm{~min}$ of daily PE administered during a school year, for elementary school males, among either the experimental school or control school. However, they found that experimental elementary school females improved their BMI significantly more than control elementary school females. Also Shephard and Lavallée (1993a) found no body fat differences in long-term effects (6 years) of daily PE classes between experimental students and their peers in control classes; while Sollerhed and Ejlertsson (2008) found no weight change effect on increasing from two to four the number of PE lessons per week. In a sample of middle school adolescents Erfle and Gamble (2015) found a weak effect in BMI percentile changes throughout one academic year in the experimental group, being only significant in the females, with a modest effect $(d=0.12)$.

UNESCO recently noted the importance of PE in elementary school for learning life skills and developing positive behavioral patterns (UNESCO 2016). The results of the present study suggest the potential impact that effective PE in primary school may have on the development of PF, and especially on the development of motor competence, which is associated to fitness as well as physical activity and weight status (Lopes et al. 2011, 2012a; Lopes, Stodden, and Rodrigues 2014; Logan et al. 2015; Robinson et al. 2015; Barnett et al. 2016).

The focus of PE curriculum has changed over time to highlight more on PF and an activity-based curriculum, thus reducing the emphasis on the development of motor competence. Malina (1991) pointed out that an emphasis on health-related physical activities at young ages may conflict with the development of a reasonable degree of proficiency in movement skills, which is one of the most important developmental tasks in childhood. The results of the present study show that an effective PE curriculum with an adequate dose per week may significantly impact health-related $\mathrm{PF}$, the development of motor competence, and may provide a protective effect against unhealthy increases in weight status. Although the main focus of the applied curriculum was on the development of motor competence, children also improved their PF with approximately 135-150 min/week of PE.

The fact that children were not randomly assigned to the classes and the sample was not representative of a larger population, constitutes a limitation of this study. In addition, while the intervention was primarily focused on MS development, the focus on PF-related activities at the beginning and end of each lesson may have influenced the resultant influence on PF. The lack of control for habitual physical activity and diet are other important constraints that may have influenced the results.

\section{Conclusion}

Two lessons per week were not enough to improve PF or body composition. Nevertheless, PE lessons demonstrated a positive effect on the development of specific MSs, even with only two lessons per week. More research is warranted to examine how quality PE can impact health and development of school children.

\section{Summary}

This study has provided insight on the potential impact of primary school PE for the development of $\mathrm{PF}$, and especially on the development of motor competence, which is associated to physical activity and weight status (Lopes et al. 2011, 2012a; Lopes, Stodden, and Rodrigues 2014; Logan et al. 2015; Robinson et al. 2015; Barnett et al. 2016).

Schools should implement a PE curriculum that includes the learning of specific MSs with an adequate dose per week (more than twice a week) to have a positive impact on health-related PF, and in the development of motor competence. This dose would promote positive child development and may provide a protective effect against unhealthy increases in weight status. 


\section{Acknowledgements}

The authors thank the Portuguese Foundation for Science and Technology for the support grant (UID/DTP/04045/ 2013 and POCI-01-0145-FEDER-006969) and UID/DTP/00617/2013.

\section{Disclosure statement}

No potential conflict of interest was reported by the authors.

\section{Funding}

This work was supported by the Portuguese Foundation for Science and Technology under Grants: UID/DTP/04045/ 2013, POCI-01-0145-FEDER-006969 and UID/DTP/00617/2013.

\section{ORCID}

Vitor P. Lopes (D) http://orcid.org/0000-0003-1599-2180

\section{References}

American Alliance for Health Physical Education Recreation and Dance 1984. AAHPERD Skills Test Manual: Basketball for Boys and Girls. Reston, VA: AAHPERD.

Barnett, Lisa M., Samuel K. Lai, Sanne L. C. Veldman, Louise L. Hardy, Dylan P. Cliff, Philip J. Morgan, Avigdor Zask, et al. 2016. "Correlates of Gross Motor Competence in Children and Adolescents: A Systematic Review and Metaanalysis." Sports Medicine 46 (11): 1663-1688. doi:10.1007/s40279-016-0495-z.

Barnett, L. M., P. Morgan, E. van Beurden, and J. R. Beard. 2008. "Perceived Sports Competence Mediates the Relationship Between Childhood Motor Skill Proficiency and Adolescent Physical Activity and Fitness: A Longitudinal Assessment." International Journal of Behavioral Nutrition and Physical Activity 5 (1): 40.

Barnett, Lisa M., Eric van Beurden, Philip J. Morgan, Lyndon O. Brooks, and John R. Beard. 2009. "Childhood Motor Skill Proficiency as a Predictor of Adolescent Physical Activity.” Journal of Adolescent Health 44 (3): 252-259.

Berg-Kelly, K., and L. Erdes. 1997. "Self-assessment of Sexual Maturity by Mid-adolescents Based on a Global Question.” Acta Paediatrica 86 (1): 10-17. doi:10.1111/j.1651-2227.1997.tb08822.x.

Beurden, E. van, L. M. Barnett, A. Zask, U. C. Dietrich, L. O. Brooks, and J. Beard. 2003. "Can We Skill and Activate Children Through Primary School Physical Education Lessons? 'Move It Groove It' - A Collaborative Health Promotion Intervention.” Preventive Medicine 36 (4): 493-501. doi:10.1016/S0091-7435(02)00044-0.

Breuer, Christoph, and Pamela Wicker. 2009. "Decreasing Sports Activity with Increasing Age? Findings from a 20Year Longitudinal and Cohort Sequence Analysis.” Research Quarterly for Exercise and Sport 80 (1): 22-31. doi:10. 1080/02701367.2009.10599526.

Cattuzzo, Maria Teresa, Rafael dos Santos Henrique, Alessandro Hervaldo Nicolai Ré, Ilana Santos de Oliveira, Bruno Machado Melo, Mariana de Sousa Moura, Rodrigo Cappato de Araújo, and David F. Stodden. 2016. "Motor Competence and Health Related Physical Fitness in Youth: A Systematic Review." Journal of Science and Medicine in Sport 19 (2): 123-129. doi:10.1016/j.jsams.2014.12.004.

Chen, Weiyun, Weimo Zhu, Steve Mason, Austin Hammond-Bennett, and Andrew Colombo-Dougovito. 2016. "Effectiveness of Quality Physical Education in Improving Students' Manipulative Skill Competency." Journal of Sport and Health Science 5 (2): 231-238. doi:10.1016/j.jshs.2015.04.005.

CNAPEF 2013. "Educação Física escolar: horários." Paper presented at the $9^{\circ}$ Congresso Nacional de Educação Física, Lisboa.

Cohen, Kristen E., Philip J. Morgan, Ronald C. Plotnikoff, Robin Callister, and David R. Lubans. 2015. "Physical Activity and Skills Intervention: SCORES Cluster Randomized Controlled Trial.” Medicine \& Science in Sports \& Exercise 47 (4): 765-74. doi:10.1249/mss.0000000000000452.

de Greeff, Johannes W., Esther Hartman, Marijke J. Mullender-Wijnsma, Roel J. Bosker, Simone Doolaard, and Chris Visscher. 2016. "Effect of Physically Active Academic Lessons on Body Mass Index and Physical Fitness in Primary School Children.” Journal of School Health 86 (5): 346-352. doi:10.1111/josh.12384.

de Onis, Mercedes, Adelheid W. Onyango, Elaine Borghi, Amani Siyam, Chizuru Nishida, and Jonathan Siekmann. 2007. "Development of a WHO Growth Reference for School-aged Children and Adolescents." Bulletin of the World Health Organization 85 (9): 660-667. doi:10.2471/BLT.07.043497. 
Dudley, Dean, Anthony Okely, Philip Pearson, and Wayne Cotton. 2011. "A Systematic Review of the Effectiveness of Physical Education and School Sport Interventions Targeting Physical Activity, Movement Skills and Enjoyment of Physical Activity." European Physical Education Review 17 (3): 353-378. doi:10.1177/1356336x11416734.

D’Hondt, Eva, Benedicte Deforche, Ilse Gentier, Joke Verstuyf, Roel Vaeyens, Ilse De Bourdeaudhuij, Renaat Philippaerts, and Matthieu Lenoir. 2014. "A Longitudinal Study of Gross Motor Coordination and Weight Status in Children.” Obesity 22 (6): 1505-1511. doi:10.1002/oby.20723.

D’Hondt, Eva, Benedicte Deforche, Roel Vaeyens, Barbara Vandorpe, Joric Vandendriessche, Johan Pion, Renaat Philippaerts, Ilse de Bourdeaudhuij, and Matthieu Lenoir. 2011. "Gross Motor Coordination in Relation to Weight Status and Age in 5- to 12-Year-old Boys and Girls: A Cross-sectional Study." International Journal of Pediatric Obesity 6 (2-2): e556-e564. doi:10.3109/17477166.2010.500388.

Erfle, Stephen E., and Abigail Gamble. 2015. "Effects of Daily Physical Education on Physical Fitness and Weight Status in Middle School Adolescents.” Journal of School Health 85 (1): 27-35. doi:10.1111/josh.12217.

Ericsson, Ingegerd. 2008. "Motor Skills, Attention and Academic Achievements. An Intervention Study in School Years 1-3.” British Educational Research Journal 34 (3): 301-313. doi:10.1080/01411920701609299.

Frömel, Karel, Zbyněk Svozil, František Chmelík, Lukáš Jakubec, and Dorota Groffik. 2016. "The Role of Physical Education Lessons and Recesses in School Lifestyle of Adolescents.” Journal of School Health 86 (2): $143-151$. doi:10.1111/josh.12362.

Gallahue, D., J. Ozmun, and J. D. Goodway. 2011. Understanding Motor Development: Infants, Children, Adolescents, Adults. New York: McGraw-Hill.

Jago, Russell, Robert G. McMurray, Stanley Bassin, Laura Pyle, Steve Bruecker, John M. Jakicic, Esther Moe, Tinker Murray, and Stella L. Volpe. 2009. "Modifying Middle School Physical Education: Piloting Strategies to Increase Physical Activity." Pediatric Exercise Science 21 (2): 171-185.

Lakens, Daniël. 2013. "Calculating and Reporting Effect Sizes to Facilitate Cumulative Science: A Practical Primer for tTests and ANOVAs.” Frontiers in Psychology 4: 863. doi:10.3389/fpsyg.2013.00863.

Logan, Samuel W., Lisa M. Barnett, Jacqueline D. Goodway, and David F. Stodden. 2017. “Comparison of Performance on Process- and Product-oriented Assessments of Fundamental Motor Skills across Childhood." Journal of Sports Sciences 35 (7): 634-641. doi:10.1080/02640414.2016.1183803.

Logan, Samuel W., E. Kipling Webster, Nancy Getchell, Karin A. Pfeiffer, and Leah E. Robinson. 2015. "Relationship between Fundamental Motor Skill Competence and Physical Activity During Childhood and Adolescence: A Systematic Review.” Kinesiology Review 4 (4): 416-426. doi:10.1123/kr.2013-0012.

Logan, S. W., L. E. Robinson, A. E. Wilson, and W. A. Lucas. 2012. "Getting the Fundamentals of Movement: A Metaanalysis of the Effectiveness of Motor Skill Interventions in Children." Child: Care, Health and Development 38 (3): 305-315. doi:10.1111/j.1365-2214.2011.01307.x.

Lopes, V. P., J. A. R. Maia, L. P. Rodrigues, and R. M. Malina. 2012a. "Motor Coordination, Physical Activity and Fitness as Predictors of Longitudinal Change in Adiposity During Childhood." European Journal of Sport Science 12 (4): 384-391. doi:10.1080/17461391.2011.566368.

Lopes, Vítor P., José A. R. Maia, Luis P. Rodrigues, and Robert M. Malina. 2012b. "Motor Coordination, Physical Activity and Fitness as Predictors of Longitudinal Change in Adiposity During Childhood." European Journal of Sport Science 12 (4): 384-391. doi:10.1080/17461391.2011.566368.

Lopes, V. P, L. P. Rodrigues, J. A. R. Maia, and R. M. Malina. 2011. "Motor Coordination as Predictor of Physical Activity in Childhood." Scandinavian Journal of Medicine \& Science in Sports 21 (5): 663-669.

Lopes, V. P., David F. Stodden, Mafalda M. Bianchi, Jose A. R. Maia, and Luis P. Rodrigues. 2012. "Correlation between BMI and Motor Coordination in Children.” Journal of Science and Medicine in Sport 15 (1): 38-43. doi:10.1016/j. jsams.2011.07.005.

Lopes, V. P., D. F. Stodden, and L. P. Rodrigues. 2014. "Weight Status Is Associated with Cross-sectional Trajectories of Motor Co-ordination across Childhood." Child: Care, Health and Development 40 (6): 891-899. doi:10.1111/cch. 12127.

Löfgren, Bjarne, Robin M. Daly, Jan-Åke Nilsson, Magnus Dencker, and Magnus K. Karlsson. 2013. “An Increase in School-based Physical Education Increases Muscle Strength in Children.” Medicine \& Science in Sports \& Exercise 45 (5): 997-1003. doi:10.249/MSS.0b013e31827c0889.

Lucertini, Francesco, Liana Spazzafumo, Francesca De Lillo, Debora Centonze, Manuela Valentini, and Ario Federici. 2013. "Effectiveness of Professionally-guided Physical Education on Fitness Outcomes of Primary School Children." European Journal of Sport Science 13 (5): 582-590. doi:10.1080/17461391.2012.746732.

Malina, R. 1991. "Fitness and Performance: Adult Health and the Culture of Youth." In New Possibilities, New paradigms? edited by H. M. Eckert and R. J. Parks, 30-38. Champaign, IL: Human Kinetics.

Marshall, W. A., and J. M. Tanner. 1969. "Variations in Pattern of Pubertal Changes in Girls." Archives of Disease in Childhood 44 (235): 291-303. doi:10.1136/adc.44.235.291.

Marshall, W. A., and J. M. Tanner. 1970. "Variations in the Pattern of Pubertal Changes in Boys." Archives of Disease in Childhood 45 (239): 13-23. doi:10.1136/adc.45.239.13.

McKenzie, T. L., J. E. Alcaraz, F. N. Faucette, and J. F. Sallis. 1998. "Effects of Physical Education Program on Children's Manipulative Skills." Journal of Teaching in Physical Education 17: 327-41. 
Morgan, Philip J., Lisa M. Barnett, Dylan P. Cliff, Anthony D. Okely, Hayley A. Scott, Kristen E. Cohen, and David R. Lubans. 2013. "Fundamental Movement Skill Interventions in Youth: A Systematic Review and Meta-analysis." Pediatrics 132 (5): e1361-e1383. doi:10.1542/peds.2013-1167.

Reed, Julian, Andréa L. Maslow, Savannah Long, and Morgan Hughey. 2013. "Examining the Impact of 45 Minutes of Daily Physical Education on Cognitive Ability, Fitness Performance, and Body Composition of African American Youth." Journal of Physical Activity and Health 10 (2): 185-197.

Robinson, Leah E. 2011. "The Relationship between Perceived Physical Competence and Fundamental Motor Skills in Preschool Children." Child: Care, Health and Development 37 (4): 589-596. doi:10.1111/j.1365-2214.2010.01187.x.

Robinson, Leah E, David F Stodden, Lisa M. Barnett, Vitor P. Lopes, Samuel W. Logan, Luis P. Rodrigues, and Eva D'Hondt. 2015. "Motor Competence and its Effect on Positive Developmental Trajectories of Health." Sports Medicine 45 (9): 1273-1284. doi:10.1007/s40279-015-0351-6.

Rodrigues, Luis P., David F. Stodden, and Vítor P. Lopes. 2016. "Developmental Pathways of Change in Fitness and Motor Competence are Related to Overweight and Obesity Status at the End of Primary School." Journal of Science and Medicine in Sport 19 (1): 87-92. doi:10.1016/j.jsams.2015.01.002.

Sallis, J. F., T. L. McKenzie, J. E. Alcaraz, B. Kolody, N. Faucette, and M. F. Hovell. 1997. "The Effects of a 2-year Physical Education Program (SPARK) on Physical Activity and Fitness in Elementary School Students. Sports, Play and Active Recreation for Kids." American Journal of Public Health 87 (8): 1328-1334. doi:10.2105/AJPH. 87.8.1328.

Shephard, R. J., and H. Lavallée. 1993a. "Enhanced Physical Education and Body Fat in the Primary School Child." American Journal of Human Biology 5 (6): 697-704. doi:10.1002/ajhb.1310050612.

Shephard, R. J., and H. Lavallée. 1993b. "Impact of Enhanced Physical Education in the Prepubescent Child: Trois Rivièrs Revesited.” Pediatric Exercise Science 5: 177-189.

Shephard, R. J., and H. Lavallée. 1994. "Impact of Enhanced Physical Education on Muscle Strength of Prepubescent Child." Pediatric Exercise Science 6 (1): 75-87.

Sollerhed, A.-C., and G. Ejlertsson. 2008. "Physical Benefits of Expanded Physical Education in Primary School: Findings from a 3-Year Intervention Study in Sweden.” Scandinavian Journal of Medicine \& Science in Sports 18 (1): 102-107. doi:10.1111/j.1600-0838.2007.00636.x.

Stodden, D. F., J. D. Goodway, S. J. Langendorfer, M. A. Roberton, M. E. Rudisill, C. Garcia, and L. E. Garcia. 2008. “A Developmental Perspective on the Role of Motor Skill Competence in Physical Activity: An Emergent Relationship." Quest 60 (2): 290-306.

Tester, Garry, Tim Ackland, and Laurence Houghton. 2014. "A 30-Year Journey of Monitoring Fitness and Skill Outcomes in Physical Education: Lessons Learned and a Focus on the Future." Advances in Physical Education 4: 127-137. doi:10.4236/ape.2014.43017.

Trost, Stewart G., Russell R. Pate, James F. Sallis, Patty S. Freedson, Wendell C. Taylor, Marsha Dowda, and John Sirard. 2002. "Age and Gender Differences in Objectively Measured Physical Activity in Youth." Medicine and Science in Sports and Exercise 34 (2): 350-355.

UNESCO 2016. “Quality Physical Education Policy Project.” Accessed February 4, 2016. http://www.unesco.org/new/ en/social-and-human-sciences/themes/physical-education-and-sport/policy-project/.

WHO 2016. Final Report of the Commission on Ending Childhood Obesity. Geneva: World Health Organization. 